\title{
Cytogenetic findings indicate heterogeneity in patients with blepharophimosis, epicanthus inversus, and developmental delay
}

\author{
Mette Warburg, Merete Bugge, Karen Brøndum-Nielsen
}

\begin{abstract}
Three unrelated, mentally retarded boys with typical blepharophimosis-ptosis-epicanthus inversus syndrome (BPES) were found to have chromosomal aberrations. One of them had a del(3)(p25), another patient had a de novo translocation $t$ (2; 3), which after high resolution banding combined with chromosome painting was interpreted to be unbalanced with a loss of band q23. The third patient had a del(7)(q34). The phenotypes of the two patients with chromosome 3 related syndromes were similar, but the third also had genital malformations resembling the Smith-Lemli-Opitz syndrome. This patient had a palatal ridge, and a single mesial maxillary tooth suggesting the holoprosencephaly sequence, but CT scans of the brain were normal.
\end{abstract}

(f Med Genet 1995;32:19-24)

The blepharophimosis-ptosis-epicanthus inversus syndrome (BPES) is an autosomal dominant condition. The ears may be simple and owing to the shortness of the palpebral fissures, there is an increased inner canthal distance (ICD), that is, telecanthus. The outer canthal distance (OCD) is often normal. Two clinical types have been delineated ${ }^{1}$ : in type 1 there is reduced female fertility and early menopause, and in type 2 this is not the case.

We were interested in the chromosomal assignment of the BPES syndrome gene(s) and have searched the files of this eye clinic, which gives service to patients with developmental delay. We have found three patients with BPES and abnormal karyotypes.

Division of Paediatric Ophthalmology and Handicaps, Department of Ophthalmology, Gentofte Hospital, University of Copenhagen, 40 Sognevej, DK-2820 Gentofte, Denmark M Warburg

The J F Kennedy Institute, Department of Medical Genetics, Glostrup, Denmark M Bugge

K Brøndum-Nielsen

Correspondence to: Dr Warburg.

Received 21 March 1994 Revised version accepted for publication 22 August 1994

\section{Methods}

The patients underwent a complete paediatric and ophthalmological examination including visual acuity with Teller cards ${ }^{2}$ or optotypes, motility, slit lamp examination, ophthalmoscopy, and evaluation of facial features. Routine chromosomal analyses were done with QFQ, GTG, and high resolution RBA banding. ${ }^{3}$ Chromosome painting using commercially available biotin-dUTP labelled chromosome specific libraries (Cambio) was performed according to the manufacturer's instructions. In brief, chromosomal slides were pretreated, dehydrated, and denaturated before the application of the probe which had been denatured and preannealed. Hybridisation was

carried out overnight at $42^{\circ} \mathrm{C}$. Amplification of signals was done with avidin-FITC alternating with anti-avidin.

The fluorescent signals were viewed in a Zeiss Axioplan microscope equipped with appropriate filters and photographed. The chromosomes were counterstained with propidium iodide.

Chromosome paints of chromosomes 2 and 3 were used in case 2 , and chromosome painting of chromosome 7 as well as a chromosome 7 specific telomeric probe (ONCOR) were applied in case 3 .

\section{Case reports}

CASE 1 (280362)

This patient (fig 1A) has been described previously ${ }^{4}$ and we re-examined him when he was 31 years old. The parents were unrelated and healthy, and no similar case was known in the family. Four older and one younger sib were healthy. The mother was 36 and the father 41 years old at the birth of the patient; the mother had a radiographic examination of her stomach in the seventh week of pregnancy. The patient had epicanthus inversus, blepharophimosis, ptosis with ancillary function of the frontalis muscle when looking upwards, nystagmus, and left esotropia, and there was synophrys and telecanthus. The ICD was $48 \mathrm{~mm}$, the OCD was $103 \mathrm{~mm}$, and the palperal fissure length was $25 \mathrm{~mm}$ (15th centile).

Visual acuity was 20/90, the right optic nervehead was mildly prominent, both corneae showed keratoconus, and there was a choroidal coloboma at 6 o'clock in the left eye two disc diameters below the disc.

The external ear canals were narrow, the ears low set and posteriorly rotated; throughout childhood he had repeated middle ear inflammations. The occiput was flat and the

forehead narrow; the occipitofrontal circumference (OFC) was $55.5 \mathrm{~cm}$ (normal) at the age of 31 . The philtrum was long, the mouth was downturned, and the lips thin. There was pterygium colli and the skin was hyperextensible. The hands were broad and the fingers short, there was a supernumerary left fifth finger, and bilateral rocker bottom feet. The patient has epilepsy, and is moderately retarded. A CT scan was normal. The karyotype (fig 1B) was 46,XY,del(3)(qter $\rightarrow$ p25.3:).

CASE 2 (120973)

The mother was 23 and the father 28 years old at the birth of the patient. The paternal 

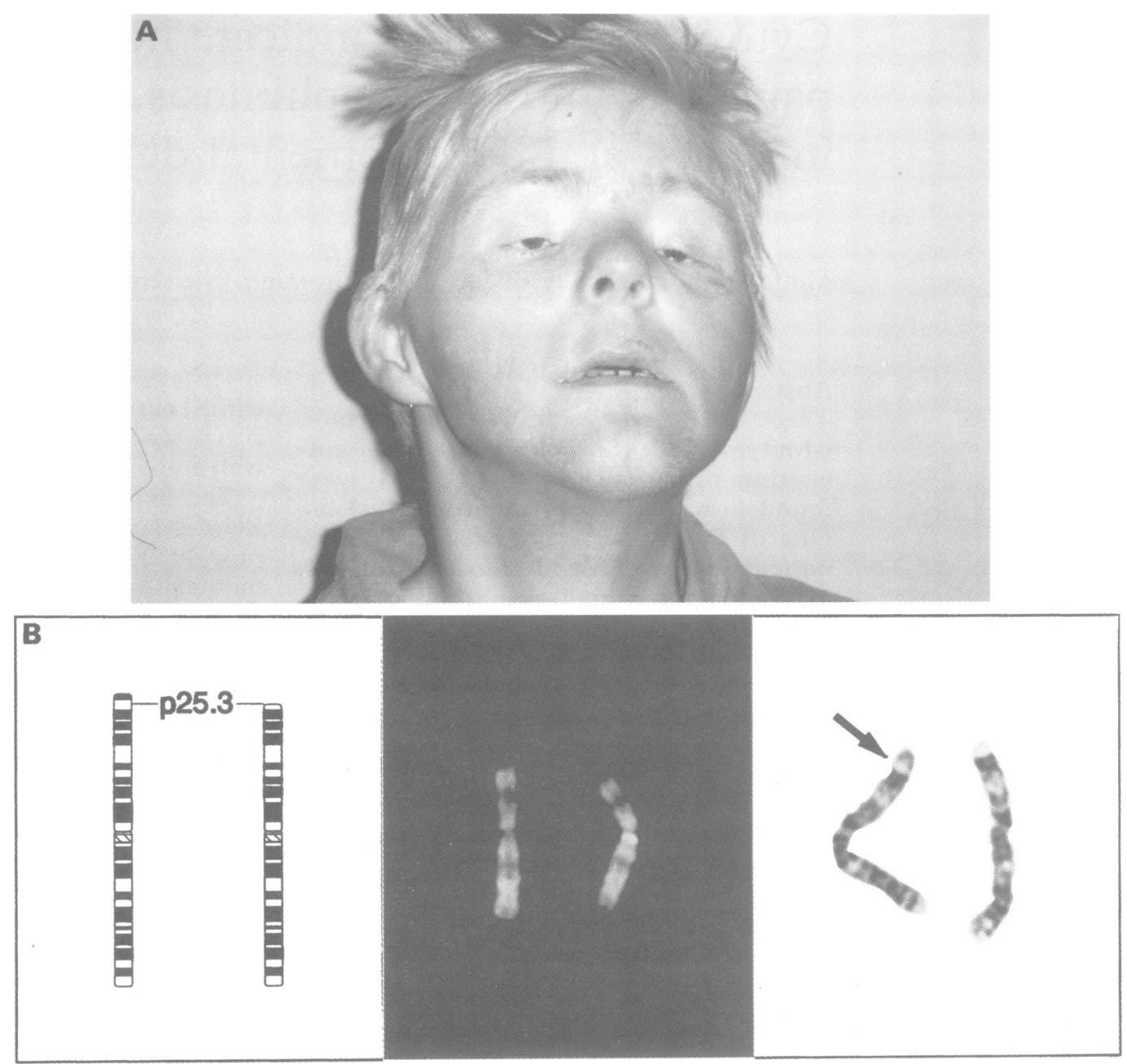

Figure 1 Case 1. (A) The patient at 31 years of age; he had blepharophimosis, ptosis, and epicanthus inversus. (B) Karyotype of case 1 showing 46,XY,del(3)(qter $\rightarrow p 25.3:)$.

grandfather had cleft lip and palate, but otherwise the family was healthy. Pregnancy was uncomplicated and delivery was by caesarian section because of cardiac decelerations. Birth was at 37 weeks of gestation. Birth weight was $2000 \mathrm{~g}$, length $43 \mathrm{~cm}$, and $\mathrm{OFC} 30 \mathrm{~cm}$. He was followed from the ages of 1 to 17 years (fig $2 \mathrm{~A})$. We found blepharophimosis, ptosis, and epicanthus inversus, a bifid uvula, retromicrognathia, low set, posteriorly rotated ears, VSD, deficiencies of the skull, and short upper extremities with ulnar deviation of the second
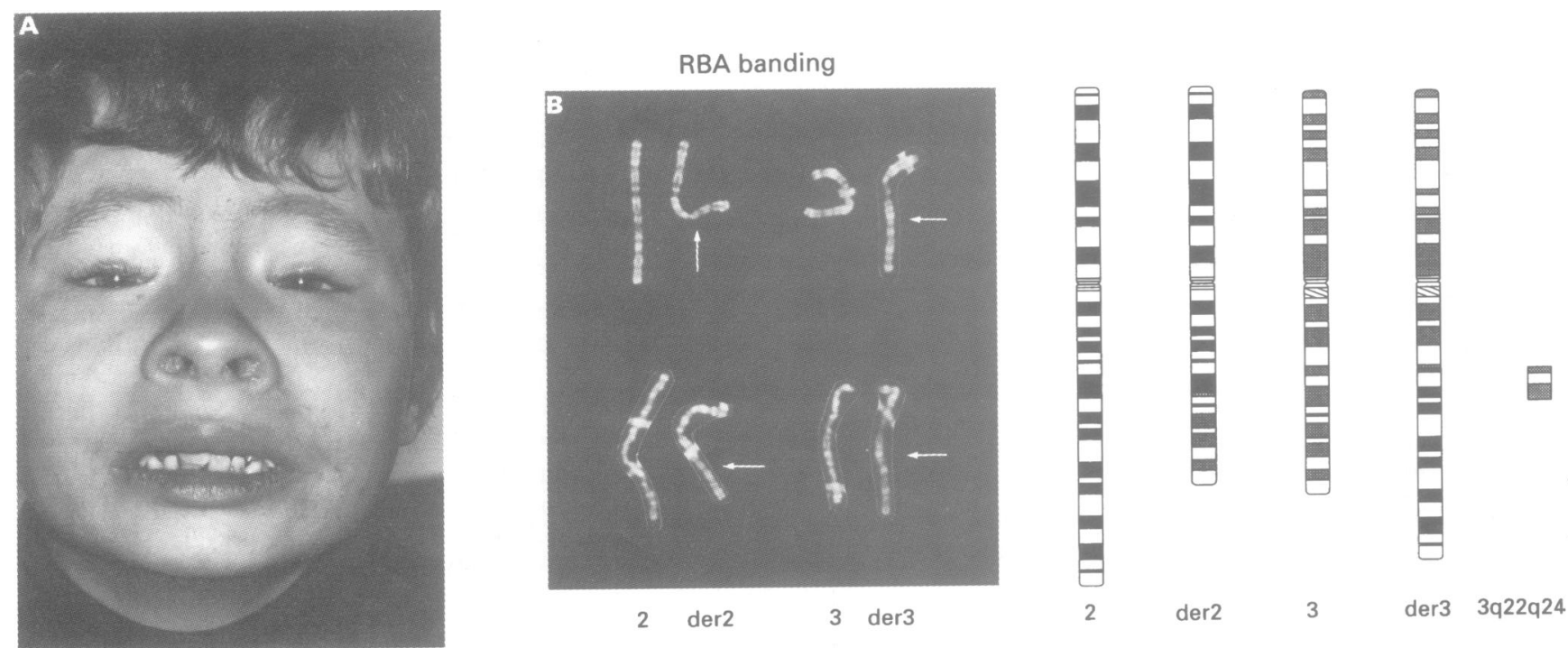

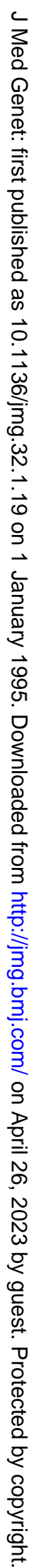

Figure 2 Case 2. (A) The patient at 17 years of age. He had blepharophimosis, ptosis, and epicanthus inversus. (B) Karyotype of case 2 showing a

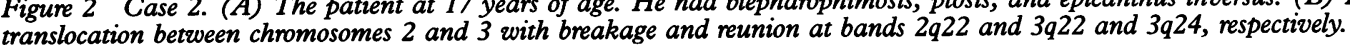




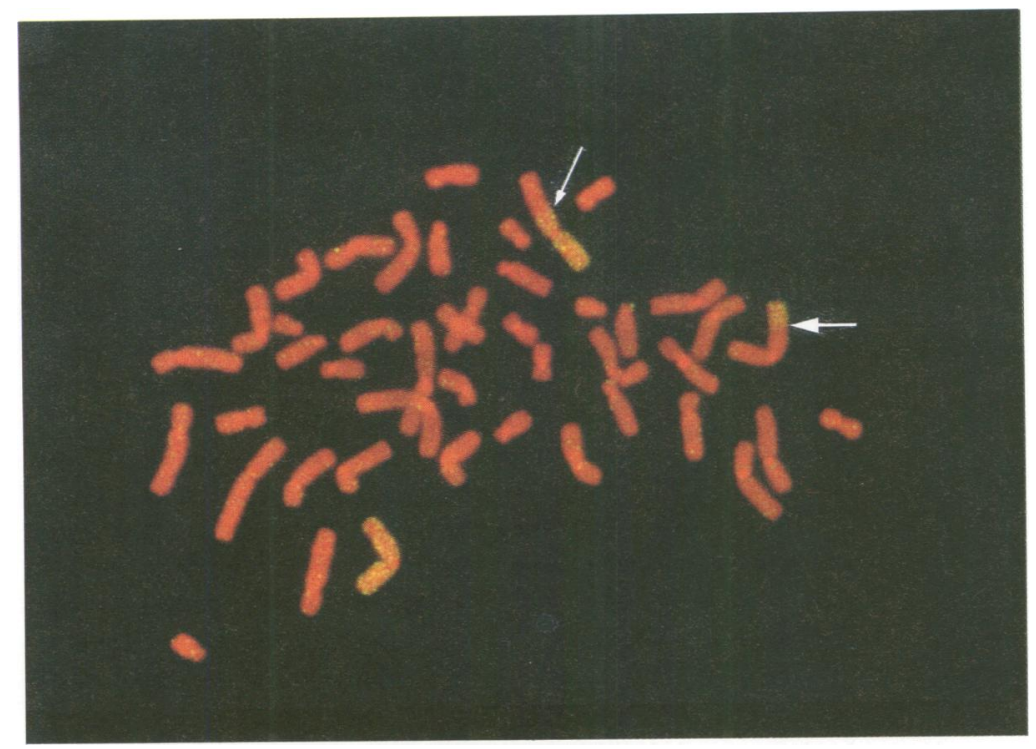

Figure 3 FISH analysis of case 2 using a chromosome 3 specific library as probe (yellow signal). The chromosomes are counterstained with propidium iodide (red). The small arrow indicates der(3) where the paint extends approximately to q22. The large arrow indicates der(2) with the translocated part of chromosome 3q24qter.
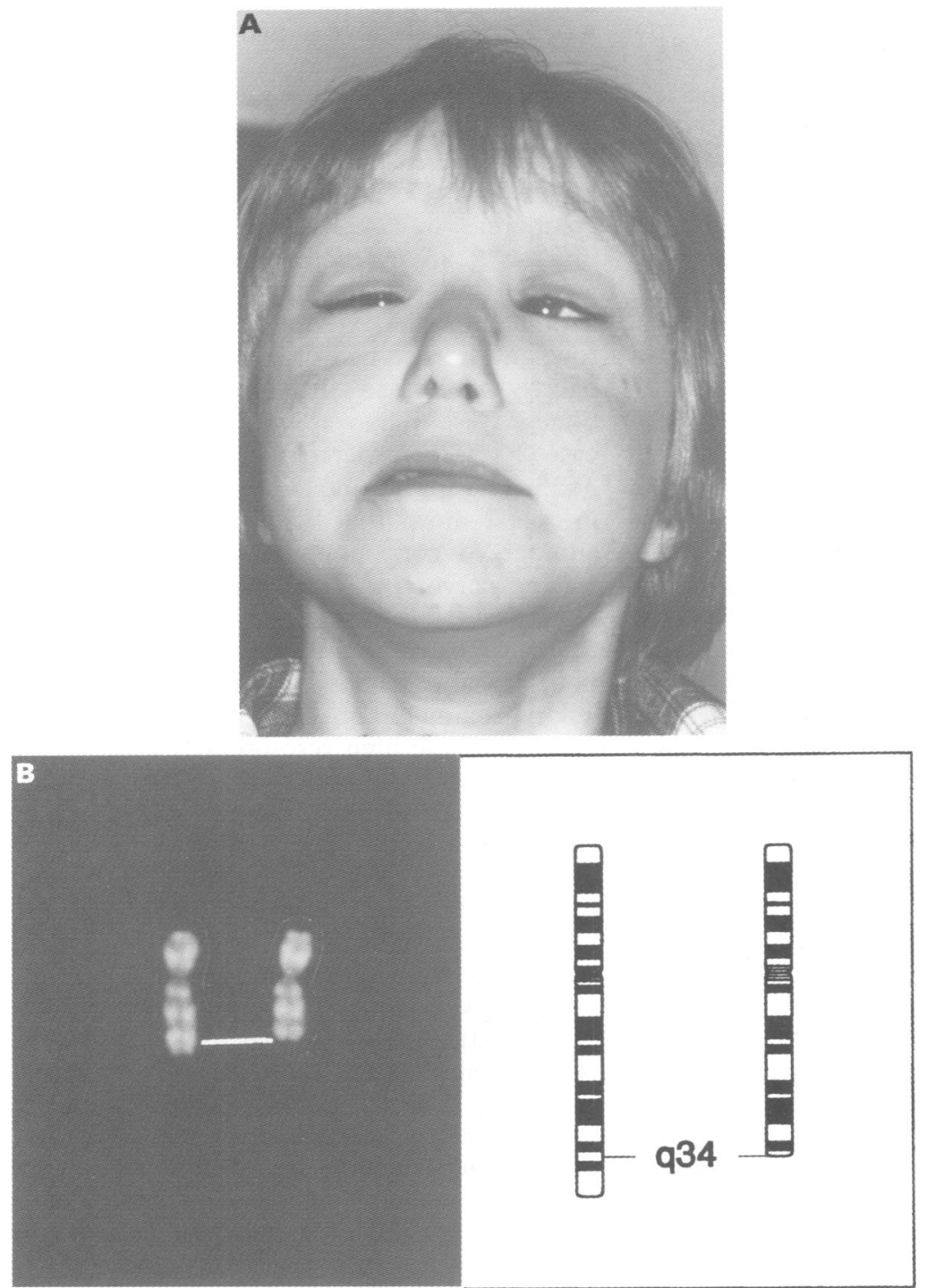

Figure 4 Case 3. (A) The patient at 20 years of age; he had blepharophimosis, ptosis, and epicanthus inversus. (B) Karyotype of case 3 showing del(7) (pter $\rightarrow$ q34:). fingers. Both second toes overrode the third and there was bilateral hallux valgus. Mobility was reduced in the hips and knees in early childhood. In childhood the femora became curved with the convexity anteriorly and laterally, and he developed a mild inferior spastic paresis. Growth and development were moderately retarded.

At 1 year of age the ICD was $27 \mathrm{~mm}$ and the OCD $64 \mathrm{~mm}$. The palpebral length was $20 \mathrm{~mm}$ (5th centile) and the maximal vertical palpebral opening was $4 \mathrm{~mm}$. Ptosis was mild in infancy but over the next two years it increased and the eyelids covered the upper half of the pupils. There was no squint and the mobility was normal except for deficient elevation of the eyes. He used his frontalis muscle as an ancillary elevator from 6 years of age. There was an abortive coloboma of the left iris, otherwise the optic media were normal. Ophthalmoscopy showed normal discs and no colobomas. Acuity was $3 / 3$ binocularly at 17 years of age.

A chromosomal translocation $\mathrm{t}(2 ; 3)$ was observed shortly after birth. High resolution $R$ banded preparations suggested that this had arisen as a result of an exchange of parts of the $\mathrm{q}$ arms of chromosomes 2 and 3. The breakpoints were difficult to determine with certainty and were initially interpreted as $2 \mathrm{q} 31$ and $3 \mathrm{q} 25$. However, FISH analysis showed that the breakpoints on chromosome 3 were unequivocally more proximal. The best fit of the banding pattern with the FISH data was highly suggestive of a small part of $3 q$ around $3 q 23$ being lost. Hence, the karyotype (fig $2 B$ ) was $46, \mathrm{XY}, \mathrm{t}(2 ; 3)(2$ pter $\rightarrow 2 \mathrm{q} 22:: 3 \mathrm{q} 24 \rightarrow 3 \mathrm{qter}$; 3 pter $\rightarrow 3 \mathrm{q} 22:: 2 \mathrm{q} 22 \rightarrow 2 \mathrm{qter})$. Fig 3 shows the chromosome 3 specific painting with three fluorescent signals: one signal on the normal chromosome 3 , which was completely painted, and one on the derivative chromosome 3 which was painted on the short arm and the proximal part of the long arm, the breakpoint being at approximately q22 (measurements not shown). The third fluorescent signal was observed on the derivative chromosome 2 . This fluorescent signal, corresponding to the distal portion of chromosome 3, was smaller than (3)(q22qter).

CASE 3 (120573)

The parents were unrelated; the mother was 25 and the father 28 years at the birth of the patient. The pregnancy was uncomplicated. A maternal grandfather had ichthyosis and a younger sister had died a few hours after birth from multiple renal cysts; necropsy showed no cerebral malformations. A maternal sister had two sons with ichthyosis and one with hypospadias. The mother's second sister had an infant who died perinatally from polycystic kidneys. The mother had a kidney ultrasound examination in her third decade; a single renal cyst was observed. Birth was at term, birth weight $2440 \mathrm{~g}$, length $51 \mathrm{~cm}$, and OFC $31 \mathrm{~cm}$. Right atresia and left stenosis of the choanae and micrognathia were observed neonatally. We followed the patient from 2 to 20 years of age (fig 4A). Growth and development were 
Clinical features in the del3p25 and 3q23 syndrome

\begin{tabular}{|c|c|c|c|c|}
\hline & \multirow[t]{2}{*}{$3 p 25^{78}$} & \multirow[t]{2}{*}{$3 q 23^{9-14}$} & \multicolumn{2}{|c|}{ Our cases } \\
\hline & & & 1 & 2 \\
\hline \multicolumn{5}{|l|}{ Face } \\
\hline Ptosis & + & + & + & + \\
\hline Blepharophimosis & + & + & + & + \\
\hline Synophrys & + & ND & + & 0 \\
\hline Epicanthus inversus & + & + & + & + \\
\hline Keratoconus & ND & ND & + & 0 \\
\hline Prominent forehead & + & 0 & 0 & 0 \\
\hline Thin upper lip & + & $(+)$ & + & 0 \\
\hline Downturned mouth & + & 0 & + & 0 \\
\hline Malformed ears & + & + & + & + \\
\hline Low set ears & + & + & + & + \\
\hline Micrognathia & + & 0 & 0 & 0 \\
\hline Hearing loss & + & 0 & + & 0 \\
\hline Triangular face & + & 0 & 0 & 0 \\
\hline Cataract & $(+)$ & 0 & 0 & 0 \\
\hline Cleft palate & $(+)$ & ND & 0 & 0 \\
\hline Microcephaly & & + & 0 & + \\
\hline \multirow{2}{*}{\multicolumn{5}{|c|}{ Skeletal anomalies }} \\
\hline & & & & \\
\hline Polydactyly & + & 0 & + & 0 \\
\hline Syndactyly & & + & 0 & 0 \\
\hline Clinodactyly & + & & - & - \\
\hline Contractures & & + & + & + \\
\hline Prominent heel & + & + & 0 & 0 \\
\hline \multicolumn{5}{|l|}{ Systemic anomalies } \\
\hline GI anomalies & + & 0 & 0 & 0 \\
\hline Renal cysts & + & 0 & ND & ND \\
\hline Congenital heart disease & + & + & 0 & + \\
\hline Retarded growth & + & + & + & + \\
\hline Mental retardation & + & + & + & + \\
\hline High mortality in infancy & + & & 0 & 0 \\
\hline
\end{tabular}

$+=$ presence of the sign, $0=$ absence, and ND $=$ not described

retarded. There was microcephaly with early closure of the fontanelles, the growth of the skull was below the 10th centile, and the left ear was low set and curled. The nostrils were small and anteverted and the philtrum was flat.

At 20 years of age visual acuity was $3 / 4 \cdot 5+3 \cdot 25$ OU with alternating esotropia. $\mathrm{He}$ had epicanthus inversus and blepharophimosis. The eyelashes were extremely long. The height of the palpebral fissures was $2 \mathrm{~mm}$, there was no function of the levator palpebrae or rectus superior muscles, and the frontalis muscle was used as an ancillary elevator; opening of the mouth increased the opening of the eyes. The ICD was $20 \mathrm{~mm}$, the OCD $83 \mathrm{~mm}$, and the OFC $50 \mathrm{~cm}$ (all below the 3rd centile).

An odontological examination at 20 years disclosed a high, narrow palate with a ridge in the middle at each side of which there was a deep furrow. The mandible was very thin and there was extreme skeletal prognathism. There was only one mesial maxillary incisor. The care workers thought that he could smell.

The holoprosencephaly sequence (HPE) was suggested because of the presence of a single mesial incisor, the shape of the palate, previous atresia and stenosis of the choanae, early closure of the fontanelles, and maxillary micrognathia. CT scans of the skull and brain, however, showed normal sinuses and ethmoid cells and no malformations of the brain.

The patient had hypospadias, a bifid preputium, and a curved penis; both testes were descended. An IV urogram was normal at 1 year of age. TORCH titres were normal. EEG showed dysrhythmia. Activities of arylsulphatase, hexosaminidase, galactosidase, fucosidase, mannosidase, and glucuronidase were all normal.

Both parents and the maternal sister had normal karyotypes. Chromosome analysis of the patient showed a de novo terminal deletion of the long arm of chromosome 7 with a breakpoint at band (7) (q34). The karyotype (fig 4C) was 46,XY,del(7) (pter $\rightarrow$ q34:). FISH analysis showed chromosome 7 centromeric as well as telomeric signals on the normal and the deleted chromosome. A small cryptic telomeric translocation can thus be excluded (data not shown).

\section{Discussion}

The BPES is an autosomal dominant disorder and clinically two types have been delineated: in type 1 there is female infertility, while this is absent in type $2,{ }^{156}$ suggesting that type 1 is a candidate for a contiguous gene syndrome. The phenotypes are similar in the two types, blepharophimosis and ptosis being the most conspicuous signs, associated with a flat and broad nasal bridge, wrinkled forehead, epicanthus inversus, and anteverted, rotated ears. Only type 1 has ovarian failure and early menopause.

Cytogenetically two different deletions on chromosome 3 have been described in patients with BPES: 16 patients with deletions of band p25.3 on the short $\operatorname{arm}^{78}$ and 11 patients with deletions of bands q23-25.9-14 The critical region was considered to be $3 \mathrm{q} 23 . .^{914}$ The phenotypes described in the two cytogenetic types are shown in the table.

Our cases 1 and 2 have classical BPES syndromes, with blepharophimosis, ptosis, epicanthus inversus, a depressed and broad nasal bridge, and telecanthus. Both boys had ocular colobomas; in case 1 this was a choroidal and in case 2 an iris coloboma. The ears were low set and posteriorly rotated. Case 1 had keratoconus, the external ear canals were narrow, and he also had unilateral postaxial polydactyly, while case 2 had defects of the cranial bones. Case 1 had a deletion of 3p25 while case 2 was considered to have a deletion of $3 q 23$. The application of chromosome painting in case 2 shows that FISH analysis can be an adjunct to conventional cytogenetics in resolving karyotypes. The banding pattern initially suggested a balanced translocation, but the chromosome painting was in favour of an unbalanced translocation bringing about a deletion proximal to $3 \mathrm{q} 25$. We then did a blinded revision of the high resolution $\mathrm{R}$ banding karyotype which supported the FISH findings. This further indicates that the critical region for BPES is $3 \mathrm{q} 23$.

Case 3 had blepharophimosis, epicanthus inversus, and ptosis. His ocular malformations were similar to those previously described in the BPES. He had hypospadias, a bifid preputium, and a curved penis. These malformations together with ptosis suggested to us for several years that he had the Smith-Lemli-Opitz (SLO) syndrome, but the parents would not allow supplementary examination of cholesterol metabolism. However, he also had features not associated with this syndrome. These were a bifid uvula, a palatal ridge, right atresia and left stenosis of the choanae, and a mesial tooth indicating HPE, features not associated with either BPES or SLO. He is alive at the age of 20 years and is moderately retarded. This 
patient had a deletion of $7 \mathrm{q} 34$.

There is one other family on record in which two sibs, monosomic for $7 \mathrm{q} 34$, showed signs of the SLO syndrome. In this family there was a translocation $t(7 ; 17)(q 34 ; p 13.1)$. A male child in this family had a $46, \mathrm{XY},-17$, $+\operatorname{der}(17) t(7 ; 17)(q 34 ; p 13.1)$ karyotype and a Miller-Dieker phenotype. His four male cousins had a $46, \mathrm{XY},-7,+\operatorname{der}(7) \mathrm{t}(7 ; 17)$ (q34;p13.1) karyotype and showed clinical syndromes suggesting SLO. ${ }^{15}$ They had microcephaly, a deep nasal bridge, epicanthus, large ears, hypospadias, micropenis, large renal cysts, congenital heart disease, overriding toes, thin ribs, and sacral malformations. One child survived and he had no blepharophimosis, ptosis, or epicanthus inversus. Our patient is much less impaired, but his dead sister and cousin had congenital renal cysts.

Holoprosencephaly (HPE) has been described in patients with deletions of $7 \mathrm{q} 36$, and patients with ring 7 with a breakpoint at $7 q 36$ have shown cyclopia or cebocephaly, but less severe phenotypes have also been reported. ${ }^{16-19}$ Thus, it has been known since the description of DeMyer et $a l^{20}$ that HPE may present facial anomalies without macroscopically abnormal brains. Although Cohen ${ }^{21}$ states that "the single maxillary incisor is nonspecific; it may occur on occasion as a striking microform of HPE, ... but it may also occur as an isolated abnormality as well in various other disorders", we believe that the association of deletion $7 q 34$, a palatal ridge, and a single maxillary incisor is sufficient for establishing a diagnosis of the HPE sequence. The clinical features in our patient showed similarities to those in three patients with translocation breakpoints at $7 \mathrm{q} 36$ described by Krauss $e t a l^{22}$ and Hatziioannou et $a l .{ }^{23}$ They had absent incisors, with only a single mesial maxillary tooth, midline facial clefts, hypoplastic nasal bones, and microcephaly. Similarly, Taysi et $a l^{24}$ described a patient with a deletion of $7 \mathrm{q} 34$ and a normal brain CT scan, who had a single mesial tooth as the only sign of HPE. In the case of Madsen et $a l^{25}$ who had a del(7)(q34), maxillary incisor anlagen were absent, and the two mesial teeth were of abnormal shape.

In HPE there is a flat nasal root, but blepharophimosis and ptosis have not been described in patients with deletions of 7q34-36. In the patients described by Taysi $e t a l^{4}$ and Madsen $e t a l,{ }^{25}$ the root of the nose was also flat and the pictures probably illustrate epicanthus inversus.

Ocular malformations in patients with deletions of the terminal part of the long arm of chromosome 7 include colobomas and microphthalmos, ${ }^{26} 27$ but such malformations are non-specific and may present in patients with deletions and duplications of almost all chromosomes. ${ }^{28}$ In this series, colobomas were observed in the patients with del $(3 p)$ and $t(2 ; 3)$.

\section{Conclusion}

BPES is a rare phenotype. We found three patients in whom BPES was associated with chromosomal anomalies out of more than 7000 retarded persons on file at the eye clinic. We can confirm that there are two locations on chromosome 3 which may give rise to the BPES, p25 and q23. The phenotypes are fairly similar, and it is not known if they correlate with the clinical types, that is, if both or only one of them may be associated with ovarian failure. If ovarian failure associated with BPES were assigned to only one of the two loci, then it might still be possible that the phenotype results from a contiguous gene defect as suggested by Smith et al. ${ }^{6}$

It was unexpected that the facial phenotype in a patient with a deletion $7 \mathrm{q} 34$ was similar to the BPES. The patient also had genital and other anomalies similar to the SLO syndrome; our findings thus confirm that a phenotype similar to the SLO phenotype may occur in deletions of $7 \mathrm{q} 34$.

It is possible that our patient has a contiguous gene defect comprising loci for (at least) one type of blepharophimosis, an SLO phenotype, and HPE.

Blepharophimosis has been classified in two clinical types; this study has confirmed that it is also a genetically heterogeneous disorder.

This paper is dedicated to Margareta Mikkelsen on the occasion of her 70th birthday.

1 Zlotogora J, Sagi M, Cohen T. The blepharophimosis, ptosis, epicanthus inversus syndrome: delineation of two types. Am f Hum Genet 1983;35:1020-7.

2 Hertz BG. Acuity card testing of retarded children. Behav Brain Res 1987;24:85-92.

3 Beck B, Mikkelsen M. Chromosomes in the Cornelia de Lange syndrome. Hum Genet 1981;59:271-6.

4 Merrild U, Berggren S, Hansen L, Mikkelsen M, Henningsen $K$. Partial deletion of the short arm of chromosome 3. Eur f Pediatr 1981;136:211-16.

5 Fraser IS, Shearman RP, Smith A, Russell MBBS. An association between blepharophimosis, resistant ovary syndrome, and true premature menopause. Fertil Steril 1988; 50:747-51.

6 Smith A, Fraser IS, Shearman RP, Russell P. Blepharophimosis plus ovarian failure: a likely candidate for a contiguous gene syndrome. 7 Med Genet 1989;26:434-8.

Narahara K, Kikkawa K, Murakami M, et al. Loss of the 3 p25.3 band is critical in the manifestation of $\operatorname{del}(3 p)$ syndrome: karyotype-phenotype correlation in cases with deficiency of the distal portion of the short arm of chromosome 3. Am F Med Genet 1990;35:269-73.

8 Mowrey PN, Chorney MJ, Venditi CP, et al. Clinical and molecular analyses of deletion 3p25-pter syndrome. Am f Med Genet 1993;46:623-9.

9 Fujita H, Meng J, Kawamura $M$, Tozuka N, Ishii F, Tanaka $\mathrm{N}$. Boy with a chromosome $\operatorname{del}(3)$ (q12q23) and blepharophimosis syndrome. Am $\mathcal{F}$ Med Genet 1992;44:4346.

10 Fryns JP, Strømme P, Van den Berghe H. Further evidence for the location of the blepharophimosis syndrome (BPES) at 3q22.3-q23. Clin Genet 1993;44:149-51.

11 Ishikiriyama $S$, Goto $M$. Blepharophimosis sequence (BPES) and microcephaly in a girl with $\operatorname{del}(3)(\mathrm{q} 22.2 \mathrm{q} 23)$ : a putative gene responsible for microcephaly close to the BPES gene? Am $\mathcal{f}$ Med Genet 1993;47:487-9.

12 Jewett T, Rao PN, Weaver RG, Stewart W, Thomas IT Pettenati MJ. Blepharophimosis, ptosis, and epicanthus inversus syndrome (BPES) associated with interstitial deletion of band 3q22.3 and 3q23. Am $\mathcal{f}$ Med Genet 1993; 47:1147-50.

13 De Almeida JCC, Llerena JC Jr, Neto JBG, Jung M, Martins RR. Another example favouring the location of BPES at 3q2. F Med Genet 1993;30:86-8.

14 Boccone L, Meloni A, Falchi AM, Usai V, Cao A. Blepharophimosis, ptosis, epicanthus inversus syndrome, a new case associated with de novo balanced autosoma translocation (46,XY,t(3;7)(q23;q32). Am f Med Genet 1994;51:258-9.

5 Berry R, Wilson $\mathrm{H}$, Robinson J, et al. Apparent SmithLemli-Opitz syndrome and Miller-Dieker syndrome in a family with segregating translocation $\mathrm{t}(7 ; 17)$ (q34;p13.1) Am F Med Genet 1989;34:358-65.

16 Bogart MH, Cunniff C, Bradshaw C, Jones $\mathrm{KL}$, Jones OW. Terminal deletions of the long arms of chromosomes 7 : five new cases. Am $\mathcal{F}$ Med Genet 1990;36:53-5.

17 Lurie IW, Ilyina HG, Podleschuk LV, Gorelik LB, Zaletajev DV. Chromosome 7 abnormalities in parents of children with holoprosencephaly and hydronephrosis. Am $\mathcal{F ~ M e d}$
Genet 1990;35;286-8. 
18 Morichon-Delvallez N, Delezoide AL, Vekemans M. Holoprosencephaly and sacral agenesis in a fetus with a ter-
minal deletion $7 \mathrm{q} 36 \rightarrow 7 \mathrm{qter}$. $\mathcal{Y}$ Med Genet 1993;30:521-4.

19 Tsukamoto $H$, Sakai $N$, Taniike $M$, et al. Case of ring chromosome 7: the first report of neuropathological find-

20 DeMyer WE, Zeman W, Palmer CG. The face predicts the brain: diagnostic significance of median facial anomalies for holoprosencephalyy (arhinencephaly). Pediatrics 1964; 34:256-63.

21 Cohen MM Jr. Perspectives on holoprosencephaly. Part III. Spectra, distinctions, continuities, and discontinuities. Am f Med Genet 1989:34:271-88.

22 Krauss CM, Liptak KJ, Aggarwal A, Robinson D. Inheritance and phenotypic expression of a $t(7 ; 9)$ (q36; q34)mat. Am f Med Genet 1989;34:514-19.

23 Hatziioannou AG, Krauss CM, Lewis MB, Halazonetis TD.
Familial holoprosencephaly associated with a translocation breakpoint at chromosomal position $7 \mathrm{q} 36$. Am $f$ Med Genet 1991;40:201-5. 24 Taysi K, Burde RM, Rohrbaugh JR. Terminal long arm deletion of chromosome 7 and retino-choroidal coloboma. Ann Genet (Paris) 1982;25:159-61.

25 Madsen HN, Lundsteen C, Steinrud J. A case of partial deletion of the long arm of chromosome 7 (7q34 $\rightarrow$ 7qter) Dan Med Bull 1983;30:14-16.

26 Friedrich U, Østerballe O, Stenbjerg S, Jørgensen J. A girl with karyotype 46,XX,del(7)(pter $\rightarrow$ q32:). Hum Genet 979;51:231-5.

27 Serup L. Interstitial deletion of the long arm of chromosome 7. Hum Genet 1980;54:19-23.

28 Warburg M, Friedrich U. Coloboma and microphthalmos in chromosomal aberrations. Ophthal Paediatr Genet 1987; 8:105-18. 